\title{
A INVENÇÃO DOS QUADRINHOS AUTORAIS: UMA BREVE HISTÓRIA DA ARTE DA SEGUNDA METADE DO SÉCULO XX
}

\author{
ALEXANDRE LINCK VARGAS \\ UnIVERSIDADE DO SUL DE SANTA CATARINA (UNISUL)
}

\begin{abstract}
RESUMO: É preciso estabelecer a diferença entre o autor de quadrinhos e a genericamente denominada "história em quadrinhos autoral", de modo a recuperar desta o traço de sua invenção, sua forja histórica. Costumeiramente é demarcada a invenção dos quadrinhos autorais nos anos 1960, sobretudo pela cultura dos comix. Contudo, o que este artigo se propõe é mostrar que havia um processo maior e mais complexo em curso. Sem dúvida, os anos 1960 foram um tempo propício para o surgimento discursivo das HQs autorais, afinal, a autoria ocupava um lugar privilegiado nas disputas da teoria literária e cinematográfica. Porém, desde os anos 1950, o mundo dos quadrinhos já assistia a mudanças significativas, fosse pelas editoras atribuindo um valor autoral por vezes hiperbolizado às revistas em quadrinhos, fosse 0 público leitor por meio de fanzines produzindo um "reconhecimento", fosse os próprios quadrinistas de grandes jornais em busca de um traço caligráfico. Esse percurso faria os quadrinhos autorais cindirem em três frentes na segunda metade do século, a saber, uma frente transgressiva que repudia a aceitação cultural, mas por ela se valida, uma frente aristocrática que afirma sua artisticidade sem fazer qualquer demanda, e uma frente literária que exige das histórias em quadrinhos a qualidade quase substitutiva de literatura. Não por acaso esse processo chegará, ao fim do século, articulado na substancial produção de autobiografias em quadrinhos, reagrupando essas três frentes e fazendo dos quadrinhos autorais o que deles hoje entendemos.
\end{abstract}

PALAVRAS-CHAVE: Autoria, Quadrinhos, Invenção.

ABSTRACT: It is necessary to establish the difference between the comics' author and the generically named "authorial comics", in order to recover from this last one the trace of its invention, its historical forge. The invention of authorial comics is usually delimitated in the 1960, especially by the comix culture. However, this article purposes itself to show that there was a larger and more complex process underway. Without a doubt, the sixties were a favorable time to the discursive appearance of authorial comics; after all, the authorship occupied a privileged place in the literary and cinematography theory. Nonetheless, since the late 1950, the comics' world have watched significant changes, either by publishers assigning a sometimes exaggerated authorial value to comics' magazines, either by a reading audience through fanzines producing "recognition", or by cartoonists of great newspapers in their search for a calligraphic trace. In the second half of the century, this course would make the authorial comics split on three fronts namely: a transgressive front that rejects the cultural acceptance, but it's validated even so; an aristocratic front that asserts its artistry without making any demands; and a literary front requiring from comics a quality almost substitute to literature. It is no accident that this process will come, at the end of the century, articulated in a substantial production of autobiographies in comics, regrouping theses three fronts and making authorial comics what we understand of them today.

KEYWORDS: Authorship, Comics, Invention. 
A autoria nas HQs sempre foi problemática no mundo dos quadrinhos. Se nos locais onde havia um autor sendo creditado omitia-se toda uma legião de assistentes - como no caso dos jornais americanos e das revistas francobelgas e japonesas -, em outros, de completa segmentação, tornava-se quase impossível articular uma autoria com segurança - é o caso das revistas americanas. Muitas vezes o crédito era dado, por questões patrimoniais, ao artista que tinha tido um papel secundário, ou mesmo não tinha papel algum, na realização de determinada $\mathrm{HQ}$. É o caso dos populares quadrinhos do Tio Patinhas, de Carl Barks, personagem este criado por ele, embora nas HQs todos os créditos fossem dados a Walt Disney. Ainda assim, havia toda uma comunidade de fãs que reconhecia a "assinatura" de um artista específico. Não por acaso, a "descoberta" de Carl Barks se deu por meio de fanzines no final da década de 1960. Uma época que deu vazão a uma franca batalha pelo lugar da autoria nas artes.

O caso da Política dos Autores da Nouvelle Vague é crucial. Enquanto ênfase do papel autoral do diretor de cinema nos anos 1960, seu ideário foi gestado pelos então jovens críticos Truffaut, Godard, Rivette, Rohmer e Chabrol na década anterior. A apreciação do estilo, cara à Política dos Autores, iria ao encontro dos diretores sufocados pelo regime hollywoodiano, encontrando a força de uma autoria em cineastas como Alfred Hitchcock. Consideradas as proporções, foi algo semelhante ao que ocorreu com a descoberta de Carl Barks. Assim como Hitchcock não roteirizou a maioria dos seus filmes, Barks não era o criador do Pato Donald, apesar de ter sido o grande quadrinista do universo pato da Disney - tudo isso parece pouco importar quando se trata de considerar a autoria a partir de um estilo. Da mesma forma, foi no espaço da crítica, e não tanto naquele ocupado por quadrinistas e cineastas, que esta exigência autoral ganhou corpo. Portanto, não está, de forma alguma, restrita ao plano dos estudos literários a crítica de Roland Barthes quando, em 1968, diz:

Dar ao texto um Autor é impor-lhe um travão, é provê-lo de um significado último, é fechar a escritura. Essa concepção convém muito à crítica, que quer dar-se então como tarefa importante descobrir o Autor (ou as suas hipóteses: a sociedade, a história, a psique, a liberdade) sob a obra: encontrado o Autor, o texto está "explicado", o crítico venceu. ${ }^{1}$

Essa intimidade entre crítica e autoria já aparece na experiência americana dos quadrinhos, ainda nos anos 1950, nos fanzines sobre a Entertaining Comics (EC Comics). Diferentemente da maioria das editoras, a EC creditava seus autores, e, em 1953, criou o EC Fan-Addict Club que emitia o Fan-Addict Bulletin com anúncios sobre novos lançamentos e notícias triviais sobre a vida dos autores. Junto disso havia o incentivo de que os leitores trocassem correspondências para permutar ou vender edições antigas, além do anúncio do fanzine EC Fan Bulletin, o que acabou forjando toda uma

\footnotetext{
${ }^{1}$ BARTHES, Roland. A morte do autor. In: O rumor da língua. São Paulo: Brasiliense, 1988, p. 69.
} 
comunidade de fãs e publicações a respeito ${ }^{2}$. Portanto, não é exagero dizer que a crítica americana dos quadrinhos nasce, mais sistematicamente, junto do reconhecimento da autoria - algo que vai explicar a busca por Barks na década seguinte. Esse amálgama pouco mudou nos dias de hoje. Ainda é comum toda uma arqueologia das intenções dos autores, o que se complica quando parte para atividades tão segmentadas e pouco estruturadas dentro de um "respeito" às vontades do autor. Tais desafios na busca da autoria são bastante comuns, às vezes assumindo a dimensão de um esporte ou abrindo para alguma reivindicação política, como é o caso de todo um habitual clamor a favor dos autores, portadores da possibilidade humana da apreciação crítica, contra certas decisões legais ou empresariais, frias e impessoais.

De alguma forma, os quadrinhos ocuparam a sarjeta entre os quadros do cinema e da literatura no que diz respeito à função do autor nos anos 1960. Para o cinema, o encontro da autoria estava na busca de um sujeito capaz de vencer a máquina, algo semelhante ao que Walter Benjamin ${ }^{3}$ percebe na catarse do público de operários que viam no ator de cinema o sujeito capaz de subjugar o maquinário - na maioria das vezes - cinematográfico. Para uma indústria, como a do cinema, o filme nasce como um produto reproduzido em massa, onde existe um gerente responsável, um diretor que somente direciona outros profissionais envolvidos na realização de determinada película. Atribuir a autoria ao diretor foi, naquele momento, algo bastante irruptivo no jogo de forças que permeavam toda uma percepção da atividade cinematográfica. Uma invenção, portanto. Embora se privilegiasse o diretor, não parece por acaso que, a partir dos anos 1970, se dê mais amplamente a produção de créditos finais em que constam todos os integrantes do filme. Afinal, se outrora o crédito era sinal de prestígio, como fora, por exemplo, no star system ou no impressionismo francês, agora ele era a justeza de uma autoria negligenciada perante o prevalecimento da máquina. Ou seja, não bastava mais o filme estar tecnicamente impecável, era preciso dar todos os nomes envolvidos daqueles heróis que foram os vitoriosos da técnica.

Do lado quase que oposto, estava a literatura. Conforme Barthes, a morte do autor já rondava a literatura francesa desde o século XIX, passando por Mallarmé, Valéry, Proust e a escrita automática dos surrealistas. Na experiência literária, sem o ruído da legitimação autoral que permeava o cinema e os quadrinhos, era necessário justamente dar a ouvir o quão ruidosa era a concepção de autor para a literatura. Condicionado ao esquema vida e obra, o autor tornou-se o semblante de uma potencialidade negada, tirando da leitura a possibilidade de qualquer voo que não se dê na rota definida pela decifração do autor. Ou seja, toda leitura do livro era subjugada por uma virtual leitura anterior, que era a do autor. O esforço pela morte do autor estava, justamente, em fazer perceber o absurdo desse procedimento que invertia a mais simples constatação de que era a partir da leitura do livro que inventávamos o autor, e

\footnotetext{
2 BEATY, Bart. Comics versus art. Toronto: University Of Toronto, 2012, p. 110.

${ }^{3}$ BENJAMIN, Walter. A obra de arte na era de sua reprodutibilidade técnica. In: Magia e técnica, arte e política. São Paulo: Brasiliense, 1994, p. 179.
} 
não vice-versa. Curiosamente, o estilo, definidor daquilo que reúne pertenças dentro de um autor pela imagem de seu movimento e de seu tempo, foi reconhecido pela literatura como uma prisão, enquanto o cinema o enxergou como uma sala de estar onde o diretor é o detentor da morada. Nesse ínterim, os quadrinhos parecem ter encontrado uma oportunidade aberta por estes dois movimentos: ao mesmo tempo em que buscou os mesmos argumentos estilísticos que fundamentam a autoria no cinema, aproveitou-se da recusa da literatura, substituindo-a, de alguma maneira, como o novo objeto de leitura em que os novos autores podiam ser (re)encontrados.

Na experiência americana, a autoria nos quadrinhos no seu grau máximo costuma ser associada aos quadrinhos underground, ao mundo das publicações "alternativas". O grande marco é a revista Zap Comix, de Robert Crumb, em 1968. Não apenas relevante pela tônica da autoexpressão, os comix - comics underground - foram uma resposta tanto ao moralismo do Comics Code, resultado das campanhas da década anterior, quanto ao sistema econômico que fazia circular as HQs, optando por toda uma rede alternativa, como as head shops enquanto ponto de venda. Somado a tudo isso, a importância da Zap Comix encarna-se em uma imagem fundacional: Crumb vendendo quadrinhos, junto de sua mulher grávida e alguns amigos, com um carrinho de bebê para transportar os exemplares do primeiro número da revista na Haight-Ashbury, no início de 1968, seio do movimento hippie. "O quadro pitoresco representa a Belém do nascimento dos quadrinhos underground"4 Crescendo e multiplicando-se enormemente, os comix explodiram naqueles anos, e seu ideário libertário e autoral até hoje sustenta o prolífico mercado alternativo de quadrinhos. Porém, não esqueçamos, estamos diante de uma invenção, uma forja intelectual.

Não que a Zap Comix não tenha sua importância enquanto ruptura, porém, da mesma forma, é preciso fazer ver o que permanecia em continuidade. 0 próprio Crumb jamais deixou de citar a influência de revistas como a satírica Mad, sob a editoria de Harvey Kurtzman, entre 1952 e 1956. Contudo, esse aspecto diz respeito quase que exclusivamente à temática debochada e a certo estilo gráfico agressivo que permeava os comix, o que acaba deixando de fora outras características igualmente importantes. Isso se tornará mais perceptível a partir da observação do paradigma autoral que estava em curso. Conforme sabemos, a EC já praticava, nos anos 1950, a atribuição de crédito aos autores. Mas isso não era, necessariamente, a invenção de um autor no sentido mais próximo de "expressão do eu", afinal, havia ainda todo um controle editorial, restrições temáticas e pouco interesse por parte dos artistas na busca por uma autoexpressividade.

Entre a EC Comics e a Zap Comix, merece maiores cuidados uma espécie de elo perdido chamado Witzend. Publicada originalmente em 1966, com duas edições em 1967 e outras duas no ano de estreia da Zap, Witzend era uma revista editada por Wallace Wood, quadrinista que trabalhara na EC e na Mad, e que aglutinou outros ex-colegas de editora como Al Williamson, Angelo Torres, Frank Frazetta e o próprio Harvey Kurtzman. Além disso,

\footnotetext{
${ }^{4}$ GARCÍA, Santiago. A novela gráfica. São Paulo: Martins Fontes, 2012, p. 162.
} 
contaria com contribuições de desenhistas populares da Marvel, como Jack Kirby, Steve Ditko e Jim Steranko, entre outros quadrinistas como Archie Goodwin, Dan Adkins, Gil Kane, Bill Pearson e o jovem Art Spiegelman. Em termos editoriais, Witzend era dedicada somente ao culto da liberdade autoral. Por isso era possível encontrar numa mesma edição histórias de ficção científica ou aventura pouco distantes do que já era publicado na época, assim como sátiras, nudez e experimentalismos mais ousados. Também havia a publicação de contos, poemas, ilustrações e textos bastante elogiosos aos autores de quadrinhos. Witzend pretendia-se "o maior conjunto de arte gráfica e literária na história da forma ilustrada narrativa" ${ }^{\prime 5}$. Chama atenção tamanha pretensão ser admitida - e, ao que parece, tida como possível - na medida em que tão simplesmente a autoria fosse livre para se manifestar. Prevalece, portanto, 0 entendimento de que, com a autoria sem as habituais amarras editoriais, a arte dos quadrinhos poderia, enfim, tomar forma. Porém, se esta trajetória explica como a autoria seria elevada ao valor artístico, permitindo o reconhecimento da Zap a partir de sua mais violenta autoexpressão, isso pouco nos conta sobre o estilo da revista propriamente dito. Essa história se dará mais precisamente noutro lugar.

No pós-guerra, enquanto a campanha antiquadrinhos se concentrava nas revistas, os jornais assistiam ao surgimento de novas tiras, como Pogo, de Wal Kelly, em 1948, e Peanuts, de Charles Schulz, em 1950. Enquanto Pogo ainda herdava todo o peso de uma graciosidade tecnicamente bem-acabada ao estilo Disney, Peanuts apresentava um traço mais rascunhado, ora acanhado, ora incisivo, porém sobremaneira marcante como o gesto de que um cartunista havia trabalhado ali. A presença de um traço caligráfico, que traz à tona a assinatura do autor a partir da ênfase do seu rabisco enquanto um processo, algo exposto entre o desenho e a arte-finalização, iria intensificar-se com artistas como Johnny Hart, com B.C., em 1958, e na sua parceria com o desenhista Brant Parker, na tira de 1964, The Wizard of Id. Porém, ainda mais marcante seria o trabalho de Jules Feiffer: sua tira, de 1956, que se chamaria Sick Sick Sick e, depois, Feiffer, não só concatenava a periodicidade principalmente a partir da mera assinatura do autor - diferentemente das outras que eram intermediadas pelos personagens recorrentes -, como era dono de um grafismo sinuoso, obsessivo e altamente gestual. Em Feiffer, a imperfeição de traços que não se fecham, os rostos repetidos que nunca são exatamente iguais e o minimalismo dos cenários, quando existentes, dão ao seu trabalho um caligrafismo que está mais para a personalização da escrita do que para a técnica representacionista do desenho.

No Brasil, um pouco mais tardiamente teríamos o traço de Henfil. Hiroshima meu humor, seu primeiro livro, de 1966, reunia charges publicadas no ano anterior e trazia o já esperado humor ácido de um chargista. Com um traço intenso, nervoso, no limite do rabisco, mas capaz de, perfeitamente, dar

\footnotetext{
${ }^{5}$ WOOD, Wallce et al. And in the offing. In: ONG, Tony; WHITE, Preston (Org.). Witzend. Seattle: Fantagraphics, v. 1, p. 11, 2014 (tradução minha).
} 
identidade ao que era esperado figurar. "Meu desenho é caligráfico. Desenho como escrevo." ${ }^{\prime 6}$.

Dessa forma, seja por Schulz, Hart e Feiffer, seja na experiência brasileira com Henfil, os comix herdarão uma tradição em que o traço, o que dá forma ao desenho, é, por si só, uma assinatura, uma maneira muito peculiar, intensa e íntima de constituir a caligrafia de um autor - algo que aparecerá com bastante força em outros artistas da Zap. Identificar uma história do traço como caligrafia, portanto, parece dar mais conta de uma narrativa visual do discurso de autoexpressão, que os comix tomarão de assalto, do que simplesmente o modelo de publicação independente como espaço da autonomia plena, pois é necessário lembrar, a Zap Comix no 1 possuía um editor, Don Donahue.

Contudo, para além dos quadrinhos americanos, o movimento em direção à autoria também ocorria em outros lugares. No Japão, enquanto o mangá de Tóquio seguia a escola de Osamu Tezuka, em Osaka se desenvolvia o gekigá - figuras dramáticas -, termo este cunhado por Yoshihiro Tatsumi, em 1957, e que se referia a um mangá voltado para um público mais adulto. Assim como os comix precisaram encontrar uma forma alternativa de veiculação pelas head shops, os gekigás estavam disponíveis por meio das kashibonya, livrarias de aluguel, o que permitia uma produção de acesso barato, transitório e sem passar pela censura editorial. Nos anos 1960, porém, com a recuperação econômica do país, as livrarias de aluguel desapareceram, e muitos dos artistas do gekigá foram incorporados pela indústria de Tóquio ${ }^{7}$. Foi nesse contexto que surgiu, em 1964, a revista Garo, palavra que quer dizer "galeria de arte" e também é o nome de um ninja criado por Sanpei Shirato para a história $A$ lenda de Kamui, destaque do primeiro número da revista. Apesar das baixas vendas em comparação com outras revistas muito mais populares, a Garo firmou-se no decorrer da década como o espaço dos quadrinhos japoneses adultos mais dedicados ao experimentalismo e à expressão autoral. ${ }^{8}$ É o caso da muito comentada e aclamada Nejishiki (A cerimônia do parafuso), de Yoshiharu Tsuge, em 1968, uma HQ onírica na qual o protagonista precisa fechar rapidamente uma ferida no braço, conduzindo a narrativa a diferentes situações absurdas. O que vale notar em Nejishiki, neste ponto, é a relação de complementariedade que há na ênfase textual pela repetição nervosa e ansiosa da narração em primeira pessoa com o próprio desenho do protagonista que aparece disposto de frente para o leitor, sendo que, ao longo dos quadros, seu corpo parecerá como uma colagem em relação ao cenário, e o seu rosto se manterá em grande parte na mesma posição frontal, o que ressalta também certa confidencialidade. Tudo isso produz uma constância e destacabilidade gráfica do eu lírico, de modo que dá à $\mathrm{HQ}$ ares de uma biografia, ou autobiografia, sem que formalmente ela seja.

\footnotetext{
${ }^{6}$ HENFIL apud CIRNE, Moacy. História e crítica dos quadrinhos brasileiros. Rio de Janeiro: Europa, 1990, p. 60.

7 GRAVETT, Paul. Mangá: Como o Japão reinventou os quadrinhos. São Paulo: Conrad, 2006, p. 42. GARCÍA, Santiago. A novela gráfica. São Paulo: Martins Fontes, 2012, p. 186.

${ }^{8}$ GRAVETT, Paul. Op. cit., p. 136.
} 
No Brasil, em 1972, mesmo ano em que Henfil lançou Zeferino, surgiria, em São Paulo, a revista Balão. Nascida no ambiente universitário e vendida de mão em mão, com mil exemplares, trazia artistas como Laerte Coutinho, Luiz Gê, Chico e Paulo Caruso, entre outros. Um apelo pela invenção de um novo autor, livre das amarras do velho mercado, conforme ficaria claro no seu editorial ${ }^{9}$. A capa do número 8 da revista, de Chico Caruso, seria bastante emblemática dessa proposta: um cowboy cavalgando uma gigantesca mão segurando uma caneta e a legenda "Uma revista contra os bandidões do HQ". O artista se torna selvagem e seu gesto passa a ser heroico.

Em 1975, com a Balão se encerrando na nona edição, nasceria, no Rio de Janeiro, a revista $O$ bicho, da mesma turma do Pasquim, por meio da editora Codecri. Criada pelo desenhista Reginaldo Fortuna, $O$ bicho tinha uma tiragem de 12 a 15 mil exemplares e maior circulação em bancas - embora também tenha durado somente nove números. ${ }^{10}$ Como a revista paulistana Grilo, de 1971, proibida de circular pela censura em 1973, O bicho também trazia quadrinhos estrangeiros conectados com o que estava acontecendo naquele momento no mundo, enfatizando a experiência americana: Robert Crumb ganharia o destaque de capa da edição $n^{\circ} 5$, e na no 7 seria publicada uma história da Witzend. Contudo, $O$ bicho também publicava trabalhos de quadrinistas brasileiros contemporâneos junto a outros mais antigos, como Ignorabus, o contador de histórias, de Vão Gogo (Millôr Fernandes) e Carlos Estevão, destaque da $4^{a}$ edição. Desde os anos 1950 havia campanhas pela nacionalização dos quadrinhos, porém, nesse contexto, é preciso considerar que a defesa por um quadrinho nacional era mais do que simplesmente uma reserva de mercado. Entrava-se na busca pela afirmação autoral, não somente por meio de um único artista, mas, principalmente, por meio da procura de uma nação que conseguisse se traduzir culturalmente numa assinatura.

Porém, é na França que encontraremos de modo mais elementar as forças que encontraram no autor um lapso entre aquele que havia sido animado no cinema e morto na literatura. Diferentemente dos americanos, os franceses não assistiram a uma contracultura dos quadrinhos de forma tão abrupta. Isso se deve, em grande parte, ao fato de o mercado ser mais maleável e saber incorporar mudanças, ainda que com alguma disputa capaz de oxigenar a questão da autoria. Mesmo assim, existem alguns princípios em comum. Em 1945, René Goscinny se mudaria para Nova York, onde conheceria Harvey Kurtzman e, por meio deste, os artistas fundadores da revista Mad, Will Elder, Jack Davis, John Severin, entre outros. Esse contato seria importante para Goscinny que, em 1959, na França, lançaria a revista Pilote. ${ }^{11}$ Se a tradição satírica da Mad era de um humor por vezes agressivo, a Pilote estava mais para o sarcasmo, como seria o caso de Asterix, personagem de estreia, escrito por Goscinny e desenhado por Albert Uderzo. A história da aldeia povoada pelos

\footnotetext{
${ }^{9}$ CIRNE, Moacy. Uma introdução política aos quadrinhos. Rio de Janeiro: Achiamé, 1982, p. 97.

${ }^{10}$ CIRNE, Moacy. História e crítica dos quadrinhos brasileiros. Rio de Janeiro: Europa, 1990, p. 71.

${ }^{11}$ GARCÍA, Santiago. A novela gráfica. São Paulo: Martins Fontes, 2012, p. 179.
} 
irredutíveis gauleses junto do grafismo que a fez tão popular entre as crianças vem acompanhada por uma série de comentários sarcásticos sobre a difícil convivência nacional, cultural e idiomática na Europa, onde a maior dignidade é tão somente ser digno de riso. Na década seguinte, contudo, Pilote abriria espaço para jovens autores de gêneros distintos, não se restringindo ao humor. Ao mesmo tempo certa adultidade seria impulsionada, fazendo a Pilote assistir e ao mesmo tempo concorrer com revistas como Hara-Kiri, de 1960, Charlie Mensuel, de 1967 e, fundamentalmente, L'Echo des Savanes, de 1972.

L'Echo des Savanes tornou claro o que seus leitores eram: "somente adultos" constava na capa. Influenciada pelo underground americano (o trabalho de Robert Crumb havia aparecido na revista Actue/ de 1970), artistas se dispuseram a chocar pela natureza do material, que frequentemente implicava em imagens explícitas de sexo ou escatologia. ${ }^{12}$

L'Echo des Savanes era formada por Claire Bretécher, Nikita Mandryka e Marcel Gotlib, todos ex-colaboradores da Pilote, que a deixaram após restrições editoriais de Goscinny. Sendo o que havia de mais próximo da sensação de ruptura ocasionada pela Zap Comix, L'Echo des Savanes foi a revista que, para Groensteen ${ }^{13}$, fez os quadrinhos franceses adentrarem definitivamente na idade adulta no século XX.

A proximidade entre adultidade e a busca por (auto)(r)reconhecimento autoral não é uma mera coincidência. Enquanto a criança se dá por satisfeita com a mágica, 0 adulto quer saber o que está por trás do truque. A identificação dos autores, cara ao fandom americano, traz em si o gesto de buscar reconhecer o que está operando numa $\mathrm{HQ}$ por meio do indivíduo, da intenção e da técnica.

Portanto, um autor que se identifica com a necessidade de autoexpressão muito provavelmente se apresentará como aquele que está disposto a exibir o seu próprio segredo, dando como produto aquilo que está, supostamente, por trás da história e que só um adulto terá a malícia para perceber - como num truque de mágica. Isso explica por que após $L$ 'Echo des Savanes aconteceria, no mercado franco-belga, toda uma expansão de produções cada vez mais radicalizadas na expressão do autor.

Nessa direção, na segunda metade dos anos 1970, três revistas serão emblemáticas. Primeiramente, a Fluide Glacial, de 1975, cofundada por Gotlib, que havia deixado a L'Echo. Fluide Glacial atendia à intenção autoral de radicalizar a proposta satírica e violenta desenvolvida na revista Mad. É famosa a capa de 1978, feita por Goossens, de Tintim injetando-se com heroína. Por sua vez, na virada do ano de 1974 para 1975, também surgiria a Métal Hurlant, com Jean Giraud (Moebius) e Philippe Druillet. Com uma proposta esotérica da

12 MILLER, Ann. Reading bande dessinée: Critical approaches to french-language comic strip. Bristol: Intellect Books, 2007, p. 25 (tradução minha).

${ }^{13}$ GROENSTEEN, Thierry. Why are comics still in search of cultural legitimization? In: HEER, Jeet; WORCESTER, Kent (Org.). A comics studies reader. Oxford: University Press Of Mississippi, 2009, p. 4. 
experiência fantástica, a Métal Hurlant fez escola no uso da ficção científica e do horror como pressupostos para aspirações mais abstratas. Enquanto com Druillet o misticismo ganha espaço com um leiaute complexo beirando a psicodelia, com Moebius a narratividade desfalece com pontilhados e hachuras na grandiloquência plástica de uma projeção astral - ou, pelo menos, era esta a intenção de autor. "Pela primeira vez, ao que parecia, havia quadrinistas que produziam obras com uma proposta culta esperando explicitamente que elas fossem reconhecidas como arte" ${ }^{14}$ Por fim, com a hipérbole da intenção do autor viria também a revista ( $\dot{A}$ Suivre), em 1978, pela Casterman, editora belga tradicional especializada em quadrinhos infantis (incluindo Tintim) e literatura religiosa. Procurando agregar o prestígio das HQs da última década, ( $\dot{A}$ Suivre) propiciou considerável liberdade aos autores, principalmente no que tange à restrição de 48 páginas, comum no mercado franco-belga. Sob a proposta de se produzir romans en bande dessineé, as histórias eram divididas em capítulos e valorizavam-se qualidades literárias. No editorial constava: "Com toda a sua densidade romanesca, ( $\dot{A}$ Suivre) será a invasão bárbara da bande dessineé na literatura". ${ }^{15}$

Dessa forma, Fluide Glacial, Métal Hurlant e (Ả Suivre) seriam o índice do que cindiria os quadrinhos, até então tidos como alternativos, em três linhas. Embora por vezes complementares, mas com ênfases diferentes, essas três linhas terão a assinatura, a vida do autor, como o fio que as conduzirá a um mesmo projeto.

A primeira linha estaria mais voltada à tradição da sátira, do escracho, do humor violento, pela afirmação do underground ou manifestações anteriores, como a Mad, os quadrinhos de humor e de costumes do início do século XX ou mesmo as revistas satíricas do século XIX como a britânica Punch. Por isso, pelo próprio tradicionalismo envolvido, a Fluide Glacial serve-nos aqui mais pelo que ela ilustra no momento de seu surgimento do que pela escola que ela abriria, pois, afinal, sua novidade está no constante retorno a um modo de ser que se recusa a pertencer ao mainstream. Nessa linha, surgiria nos EUA a Weirdo, de Robert Crumb, em 1981, uma "revista louca e absurda em toda a sua essência infame, vagabunda e burra". ${ }^{16}$ No Brasil, teríamos, em 1985, a revista Chiclete com Banana, com Laerte, Angeli, Glauco e Luiz Gê. Embora essa linha dos quadrinhos não se veja exatamente como arte, não busque a legitimação - e eventual domesticação - que esse título pode inferir -, seu legado, em grande parte, é reconhecido por tais termos. Crumb, hoje, é vendido em coleções de luxo pela Taschen e pela Fantagraphics, e Piratas do Tietê, de Laerte, ganhou três volumes capa dura pela editora Devir, todas elas seguindo o projeto gráfico balizado por livros de arte.

\footnotetext{
${ }^{14}$ BEATY, Bart. Unpopular culture: transforming the european comic book in the 1990s. Toronto: University Of Toronto Press, 2007, p. 24 (tradução minha).

15 MAZUR, Dan; DANNER, Alexander. Quadrinhos: história moderna de uma arte global. São Paulo: WMF Martins Fontes, 2014, p. 131.

${ }^{16}$ CRUMB, Robert apud GARCÍA, Santiago. A novela gráfica. São Paulo: Martins Fontes, 2012, p. 201.
} 
Noutra linha se deu a Métal Hurlant, que ganharia diferentes versões e imitações pelo mundo, inclusive nos EUA e no Brasil, ajudando a solidificar algo já começado por Éric Losfeld e seus quadrinhos eróticos de luxuoso acabamento gráfico nos anos 1960. Não se tratava mais de esperar ou eventualmente rejeitar o rótulo de arte, mas de se afirmar como certo dessa qualificação, dessa categoria de ser. Essa postura aristocrática seria principalmente percebida na revista americana Raw, de 1980. Criada por Françoise Mouly e Art Spiegelman, Raw seria, em partes, a emancipação do projeto que Spiegelman lançara com a revista Arcarde, cinco anos antes, que, com a parceria de Bill Griffith, se propunha como uma antologia dos comix underground. $\mathrm{O}$ próprio gesto de reunir e reapresentar esses comix como algo para além do calor dos anos 1960, de sua descartabilidade e barata reprodução, seria um indicativo de que se buscava outro patamar. "O primeiro volume da Raw, compreendendo oito edições, estava deliberadamente em desacordo com a tradição das revistas em quadrinhos mainstream dominada pelos super-heróis, e a contracultural sensibilidade do underground por sexo e drogas". ${ }^{17}$ Sua circulação estava mais para o mundo da arte do que para 0 mundo dos quadrinhos, embora desse não se desligasse nem procurasse qualquer tipo de superação que desse a aparência de que os quadrinhos só podiam ser arte desde que não fossem o que já são. Outro fator importante, para reforçar certa percepção aurática da arte, era que cada número trazia algum elemento artesanal, como na edição 7, que tinha o canto da capa arrancado manualmente, o que valorizava a unicidade e a materialidade de cada revista. "Ou seja, o importante não eram apenas os desenhos, mas, também, as páginas nas quais estavam inscritos". ${ }^{18} \mathrm{~A}$ ironia é que, apesar de todos os investimentos da Raw para se posicionar como uma revista ímpar de arte em quadrinhos, o lançamento de Maus em suas páginas atraiu a atenção principalmente da crítica literária, deixando de lado qualquer ênfase no trabalho gráfico. Ainda assim, a proposta vanguardista e internacionalista da Raw, ao publicar Crumb e Tsuge, Tardi e Swarte, Panter e Ware, seria sentida influenciando a quebra dos formatos-padrão nos quadrinhos franceses dos anos 1990 e impulsionando aquela que seria a terceira linha dos quadrinhos.

Essa terceira linha é a invasão bárbara da literatura que ( $\dot{A}$ Suivre) promoveu. Conforme García nota, o elogio em forma de conselho de Goethe a Rodolphe Töpffer se tornaria profético quando diz que "se Töpffer não tivesse diante de si um texto tão insignificante, inventaria coisas que superariam todas as nossas expectativas". ${ }^{19}$ Essa ênfase no aprimoramento do texto perante uma forma já estabelecida como inventiva foi o que acabou norteando todo um movimento que fez as histórias em quadrinhos buscarem sua legitimação na literatura. O caminho passava pelo enfrentamento a uma suposta falta de qualidade literária dos textos, queixa comum nas campanhas antiquadrinhos. Pelo espaço de ocupação do quadro junto da restrição do número de páginas em periódicos, o fato é que os balões condicionaram uma escrita sintética,

${ }^{17}$ BEATY, Bart. Comics versus art. Toronto: University Of Toronto Press, 2012, p. 134 (tradução minha).

${ }^{18}$ GARCÍA, Santiago. Op. cit., p. 200.

${ }^{19}$ GOETHE, Johann W. V. apud GARCÍA, Santiago. Op cit., p. 52. 
direta, com pouca margem ou interesse por maiores rebusques literários que não fossem os clichês de sempre. $O$ paradigma que fez os quadrinhos, principalmente americanos, florescerem, assim como a ideia de simplificação textual por se tratar de uma comunicação voltada para a criança, também foram decisivos para todo um empobrecimento literário das HQs. Portanto, quando o valor literário dos quadrinhos passa a ser almejado, a primeira ação mais óbvia ocorre na possibilidade de escrever histórias por meio do irrestrito número de páginas. Três anos antes de a editora Casterman lançar ( $\dot{A}$ Suivre), $A$ balada do mar salgado, de Hugo Pratt, história de mais de 100 páginas publicada no formato álbum, seria um precedente de sucesso. Isso estimularia o retorno do protagonista, Corto Maltese, em novas histórias episodiadas como um romance de folhetim publicado em ( $A$ Suivre $)^{20}$.

Notadamente, em 1978, mesmo ano em que a revista ( $\dot{A}$ Suivre) era lançada, Will Eisner nos EUA publicava Um contrato com Deus e outras histórias de cortiço. Não era a primeira $\mathrm{HQ}$ a se autoproclamar uma graphic novel, nem era a primeira a sair em formato livro, mas ganhou da história o prestígio de ser simbolicamente o paradigma para uma nova era. Isso se deve ao fato de Eisner circular no ambiente dos quadrinhos autorais desde cedo por meio de tributos a seu The Spirit, dos anos 1940. Na primeira edição de Witzend, seria mencionada a valorização dos "quadrinhos como uma forma de arte"21 tendo por referência Will Eisner, e na 6a edição, de 1969, seria publicada uma extensa entrevista com Eisner por John Benson. Em 1971, Eisner seria convidado a uma convenção de quadrinhos em Nova York, onde faria contato com diferentes autores do underground, teria algumas edições de The Spirit republicadas por Denis Kitchen e faria a capa de seu comix Snarf, em $1972^{22}$. Em diferentes entrevistas, Eisner sempre repetiria que graphic novel foi um termo desesperado para conseguir posicionar sua HQ nas estantes das livrarias. Para isso se utilizou de uma editora que não publicava quadrinhos e que, embora tenha falido antes de conseguir dar maior circulação a Um contrato com Deus, conseguiu estabelecer um formato para os editores de quadrinhos ${ }^{23}$.

Contudo, a explosão da graphic nove/ e toda a pretensão literária que pese se daria com Maus, de Art Spiegelman. Lançado em 1980, na Raw, como uma pequena revista anexa, em 1986, as seis primeiras edições foram reunidas pela editora Pantheon no formato livro, com grande repercussão, e, em 1991, sairia seu segundo e último volume, resultando, em 1992, no Prêmio Especial Pulitzer. Toda essa aclamação deu corpo às diretrizes que já estavam se formando. Uma delas seria o formato livro e o estímulo a uma leitura literária dos quadrinhos. García ressalva que "poderíamos dizer que Maus recebeu tal

\footnotetext{
${ }^{20}$ MAZUR, Dan; DANNER, Alexander. Quadrinhos: história moderna de uma arte global. São Paulo: WMF Martins Fontes, 2014, p. 131.

21 WOOD, Wallace et al. In: ONG, Tony; WHITE, Preston (Org.). Witzend. Seattle: Fantagraphics, v. 1, 2014, p. 12. (tradução minha).

${ }^{22}$ GARCÍA, Santiago. Op. cit., p. 213-214.

${ }^{23}$ HATFIELD, Charles. An art of tensions. In: HEER, Jeet; WORCESTER, Kent (Org.). A comics studies reader. Oxford: University Press Of Mississippi, 2009.
} 
distinção não por ser uma história em quadrinhos, mas apesar de ser uma história em quadrinhos ${ }^{\prime \prime 24}$. Beaty ${ }^{25}$ por sua vez aponta para o efeito resultante dessa ênfase: não só o desenho passou a ser considerado uma ilustração, uma arte auxiliar que dá corpo ao principal que seriam o enredo, a trama e a narratividade no sentido mais estrito, como também elegeu o roteirista como 0 astro principal de toda uma nova linha de HQs. Isso explicaria os créditos de capa garrafais dos escritores, às vezes maiores até que o próprio título da $\mathrm{HQ}$, como no caso de Neil Gaiman, Alan Moore, Grant Morrison, entre outros. Essa postura reavivou algumas das inquietações que permeavam a pesquisa sobre os autores dos quadrinhos. Pois, se o cinema elegeu o diretor para conferir uma assinatura, as histórias em quadrinhos como um todo optaram pelo roteirista e pelo desenhista como referenciais máximos de autoria de uma obra, algo que se intensificaria, para o lado do roteirista, na febre das graphic novels. Com isso, arte-finalistas, coloristas, letristas, editores, entre tantos outros cargos, seriam mencionados como aqueles artistas que jogam novamente luz ao problema da assinatura nas histórias em quadrinhos.

Mas é com a autobiografia que a autoria encontra na invasão da literatura seu objetivo final, realinhando em partes as três vertentes. Maus, de Spiegelman, é sobre seu pai, sua relação com ele e a memória de sua família. Antes de Maus, Um contrato com Deus se refere a uma Nova York em que Eisner diz ter crescido e narra a história de um homem inconformado com Deus por ter perdido sua filha, perda esta que Eisner também sofreu. Já Corto Maltese, embora não se pretenda autobiográfico, é comumente associado com a própria biografia errante de Hugo Pratt, suas viagens para diferentes cantos do mundo, suas muitas aventuras, perigos e mulheres. Pouco importa o quanto de fantasioso há nessa construção, o que merece atenção é justamente a percepção de que isso foi construído. Na medida em que a autoria se confunde com a própria artisticidade dos quadrinhos, nada mais esperado do que toda uma validação por meio de artistas e críticos daquilo que seria de mais radical no gesto da assinatura: o quadrinizar de si. Por isso, entre os anos 1990 e 2000, a autobiografia em quadrinhos teria sua explosão com artistas como Craig Thompson, Alison Bechdel, David B., Marjane Satrapi, Kazuichi Hanawa, Guy Delisle, Joe Sacco, Art Spiegelman, Lewis Trondheim, entre tantos outros.

$\mathrm{O}$ que interessa notar é de que modo esse fim parece reunir as três linhas sob uma mesma estratégia historicamente disposta. Nos EUA, além dos comix autobiográficos, notadamente com Crumb, em 1976, Harvey Pekar começaria sua revista American Splendor, sempre tendo desenhistas colaboradores para contar periodicamente a pouco aventuresca rotina de Pekar. Se a autobiografia se afirma por meio da graphic nove/ na linha da "invasão literária" no final do século, Pekar nos serve de exemplo de que isso já estava, da mesma forma imperiosa, ocorrendo na linha sátira do underground. No Japão, o trabalho de Tsuge, nos anos 1960 e 1970, renderia o apelido de mangá watakushi (eu-quadrinhos), "nome tirado do romance watakushi japonês, que se caracteriza por narrativas altamente subjetivas na primeira

\footnotetext{
${ }^{24}$ GARCÍA, Santiago. Op. cit., p. 17.

${ }^{25}$ BEATY, Bart. Comics versus art. Toronto: University Of Toronto Press, 2012, p. 18.
} 
pessoa, muitas vezes enfatizando os sentimentos, pensamentos e desejos mais profundos e menos socialmente aceitáveis do autor" ${ }^{\prime 26}$. Se Tsuge fazia autobiografias, fazia-as na mesma linha que deu forma à Raw, ganhando relativamente pouco interesse editorial como soldado da invasão literária, embora tivesse sido publicado tanto no primeiro quanto no segundo volume da Raw. Por essa razão, casos como o de Pekar ou o de Tsuge são exemplares na medida em que mostram que a oposição entre uma suposta seriedade artística ou a falta dela, assim como uma exuberância gráfica contra uma qualidade literária está muito mais para aquilo que se dispõe enfatizar enquanto rótulo, mídia, mercado e guia de consumo, do que necessariamente para o que se poderia descolar das potencialidades de uma HQ. Não se pode esquecer que, dentre as três linhas aqui desenvolvidas nos quadrinhos, o que está em jogo não é a essência de três escolas dos quadrinhos, mas as pretensões e estratégias pelas quais três vertentes da HQ autoral encontraram ânimo e parecem ter chegado a um lugar-comum. O anúncio de fim da Zap Comix, em 1998, torna-se, então, simbólico. No seu $15^{\circ}$ número, a revista dá espaço à briga entre Crumb, que se diz de saco cheio da Zap, e Spain Rodriguez, S. Clay Wilson e Victor Moscoso que o criticam por se comportar como uma estrela em referência ao premiado documentário Crumb, de 1994, dirigido por Terry Zwigoff. A briga, que ocorreu na casa de Zwigoff, teve seu ápice na agressão física de Moscoso a Crumb. Como era de se esperar, Crumb quadrinizou em duas páginas a briga e desafiou Spain que ela fosse publicada na revista. Spain, por sua vez, topou e fez com Moscoso uma segunda versão da briga, também em duas páginas. Por fim, uma terceira versão foi feita pelo artista convidado Paul Mavrides que também produziu duas páginas. Nos últimos três quadros da HQ de Mavrides, quando Moscoso mata um arrogante Crumb com uma canetatinteiro pelas costas existe a referência à morte de Fritz the Cat, personagem de Crumb morto em 1972 depois de ter se tornado famoso com a animação longa-metragem de Ralph Bakshi ${ }^{27}$. O provisório fim da Zap na forma de uma (auto)biografia debochada, provocativa e cheia de fabulações, nos dá a imagem do que fora toda essa trajetória dos quadrinhos de autor - uma inventividade por linhas descoladas e reagrupadas por meio século de HQs.

\section{Sobre o autor}

Alexandre Linck é graduado em Cinema pela Unisul, curso que leciona atualmente. Também possui mestrado em Ciências da Linguagem (Unisul) e doutorado em Literatura (UFSC). Atua nas áreas de roteiro de cinema, teoria da imagem, crítica cultural e histórias em quadrinhos.E-mail: linck.alexandre@gmail.com.

Artigo recebido em 11 de abril de 2015.

Aprovado em 15 de junho de 2016.

${ }^{26}$ MAZUR, Dan; DANNER, Alexander. Quadrinhos: história moderna de uma arte global. São Paulo: WMF Martins Fontes, 2014, p. 81.

${ }^{27}$ CRUMB, Robert et al. In: CAMPOS, Cleiton; CAMPOS, Rogério de (ORG.). Zap Comix. São Paulo: Conrad, 2005. 